\title{
Salutary effects of moderate but not high intensity aerobic exercise training on the frequency of peripheral T-cells associated with \\ immunosenescence in older women at high risk of breast cancer: a randomized controlled trial
}

\section{Grace M Niemiro}

University of Arizona Medical Center - University Campus: Banner University Medical Center Tuscon

Adriana M Coletta

The University of Utah

\section{Nadia H Agha}

University of Houston

\section{Preteesh Leo Mylabathula}

University of Arizona Medical Center - University Campus: Banner University Medical Center Tuscon

\section{Forrest L Baker}

University of Arizona Medical Center - University Campus: Banner University Medical Center Tuscon

Abenaa M Brewster

The University of Texas MD Anderson Cancer Center

\section{Therese B Bevers}

University of Texas MD Anderson Cancer Center

\section{Enrique Fuentes-Mattei}

The University of Texas MD Anderson Cancer Center

\section{Karen Basen-Engquist}

The University of Texas MD Anderson Cancer Center

\section{Emmanuel Katsanis}

University of Arizona Medical Center - University Campus: Banner University Medical Center Tuscon

\section{Susan C Gilchrist}

University of Texas MD Anderson Cancer Center

Richard Simpson ( $\sim$ rjsimpson@email.arizona.edu )

University of Arizona https://orcid.org/0000-0002-7064-6881

Research 
Keywords: Physical activity, myokines, exercise immunology, $\beta 2$ adrenergic receptor, aging, maximal oxygen uptake, recent thymic emigrants

Posted Date: August 31st, 2021

DOI: https://doi.org/10.21203/rs.3.rs-845373/v1

License: (c) (1) This work is licensed under a Creative Commons Attribution 4.0 International License. Read Full License 


\section{Abstract}

BACKGROUND: Immunosenescence is described as age-associated changes within the immune system that are responsible for decreased immunity and increased cancer risk. Physically active individuals have fewer 'senescent' and more naïve T-cells compared to their sedentary counterparts, but it is not known if exercise training can rejuvenate 'older looking' T-cell profiles. We determined the effects of 12-weeks supervised exercise training on the frequency of T-cell subtypes in peripheral blood and their relationships with circulating levels of the muscle-derived cytokines (i.e. 'myokines') IL-6, IL-7, IL-15 and osteonectin in older women at high risk of breast cancer. The intervention involved 3 sessions/week of either high intensity interval exercise (HIIT) or moderate intensity continuous exercise (MICT) and were compared to an untrained control (UC) group.

RESULTS: HIIT decreased total granulocytes, CD4+ T-cells, CD4+ naïve T-cells, CD4+ recent thymic emigrants (RTE) and the CD4:CD8 ratio after training, whereas MICT increased total lymphocytes and CD8 effector memory (EM) T-cells. The change in total T-cells, CD4+ naïve T-cells, CD4+ central memory (CM) T-cells and CD4+ RTE was elevated after MICT compared to HIIT. Changes in $\mathrm{VO}_{2 \max }$ after training, regardless of exercise prescription, was inversely related to the change in highly differentiated CD8+ EMRA T-cells and positively related to changes in $\beta 2$-adrenergic receptor ( $\beta 2$-AR) expression on CM CD4+ and CM CD8+ T-cells. Plasma myokine levels did not change significantly among the groups after training, but individual changes in IL-7 were positively related to changes in the number of $\beta 2-A R$ expressing CD 4 naïve T cells in both exercise groups but not controls. Further, CD4 T-cells and CD4 naive T-cells were negatively related to changes in IL-6 and osteonectin after HIIT but not MICT, whereas CD8 EMRA T-cells were inversely related to changes in IL-15 after MICT but not HIIT.

CONCLUSIONS: Aerobic exercise training alters the frequency of peripheral T-cells associated with immunosenescence in middle aged/older women at high risk of breast cancer, with HIIT (pro-senescent) and MICT (anti-senescent) evoking divergent effects. Identifying the underlying mechanisms and establishing whether exercise-induced changes in T-cell frequency can alter the risk of developing breast cancer warrants investigation.

\section{Introduction}

Immunosenescence is the term used to describe age-associated declines in the normal functioning of the immune system, which has been attributed to poor vaccination responses, low-grade inflammation and increased rates of infection and cancer in older adults [1]. The peripheral T-cell compartment is particularly susceptible to age-related changes, evidenced by a lower CD4:CD8 T-cell ratio, an expansion of highly differentiated/exhausted T-cells, fewer naïve T-cells due to thymic atrophy, and the reemergence of latent herpesvirus infections (e.g. cytomegalovirus) that can drive T-cell exhaustion [2-9]. These features of immunosenescence are also correlative of future cancer occurrence and are prominent in women newly diagnosed with breast cancer $[10,11]$. 
Lifestyle factors have been revealed as a potential mitigator of immunosensence and reduced cancer risk [1]. Physical activity can lower breast cancer risk by $10-20 \%$ and is widely promoted for its positive effects on the immune system [12]. Randomized control trials in older adults have demonstrated that exercise training can improve immune responses to vaccination and lower chronic low grade inflammation [13-18]. Cross sectional studies have consistently reported 'younger looking' T-cell profiles in physically active compared to inactive individuals, even in middle age (e.g. 50-65yrs) [19]. This includes an increased CD4:CD8 T-cell ratio, fewer CD4 + and CD8 + T-cells exhibiting phenotypes associated with differentiation and exhaustion, and greater frequencies of naïve T-cells and recent thymic emigrants (RTEs) that are capable of responding to novel antigens [19]. Physically active older adults also have better control of latent herpesvirus infections and display higher serum levels of muscle-derived cytokines, particularly IL-7 and IL-15, which are known to promote thymic output and maintain peripheral T-cell numbers and function $[19,20]$.

Given the emerging evidence linking immunosenescence with breast cancer, it is possible that exercise training can lower risk by promoting favorable changes to the peripheral T-cell compartment. Regular exercise is hypothesized to purge exhausted/senescent cells from the T-cell repertoire through apoptosis, leaving 'space' for newly generated naïve T-cells to create a 'younger looking' and more efficient immune profile in a process that is facilitated by the release IL-7 and IL-15 from active skeletal muscle [21-23]. However, very few randomized control trials have determined the effects of exercise training on peripheral T-cell profiles of middle-aged/older adults, and no study, to our knowledge, has focused these efforts towards individuals who are at high risk for developing cancer. It has also been purported that exercise improves immune surveillance and lowers tumor burden due to the frequent mobilization and redistribution of effector lymphocytes via a mechanism that is dependent on catecholamine activation of lymphocyte $\beta 2$ adrenergic receptors(AR) [1]. As lymphocyte $\beta 2-A R$ sensitivity decreases with age [24, 25], there is a need to determine if exercise training will affect $\beta 2$-AR expression on blood lymphocytes in individuals at high risk of cancer.

The aim of this randomized control trial was to determine the effects of 12-weeks of structured exercise training on the frequency of blood T-cell subsets associated with immunosenescence in a population of middle-aged/older women identified as being at high risk of developing breast cancer (elevated Gail 5year risk score $(>1.66 \%)$, lifetime risk score $(>20 \%)$, history of ductal or lobular atypia, or history of ductal or lobular carcinoma in situ (non-invasive breast cancer), and to correlate these with changes in serum levels of the muscle-derived cytokines (i.e. myokines) IL-6, IL-7, IL-15 and osteonectin. We also compared moderate intensity continuous exercise training (MICT) to high intensity interval training (HIIT) due to the surging popularity, reported health benefits and comparatively low time commitment of HIIT [26]. We report here that improvements in cardiorespiratory fitness after training are inversely associated with a change in the frequency of highly differentiated CD $8+T$-cells and positively associated with changes in B2-AR expression on central memory subsets of CD4 + and CD8 + T-cells. The numbers of naïve and memory subsets of CD4 + T-cells, RTE's and the CD4:CD8 T-cell ratio were increased or maintained with MICT but reduced with HIIT. These findings indicate that aerobic exercise training is capable of altering 
the frequency of the peripheral T-cell pool and that it might be better to advocate for MICT over HIIT when prescribing exercise to improve immunity in middle aged/older women at high risk of breast cancer.

\section{Results}

\section{Participant Demographics}

Participant characteristics are listed in Table 1. Of note, no differences between participants were seen in resting heart rate, fitness levels, or resting blood pressure before intervention. 
Table 1

Demographic Data: Demographic data for all participants who completed exercise and blood sample testing.

\begin{tabular}{|c|c|c|c|c|}
\hline Demographic Mean (SD) & & Pre & Post & $\begin{array}{l}\text { Within Subjects p- } \\
\text { value }\end{array}$ \\
\hline \multirow[t]{3}{*}{ Weight (kg) } & HIIT & $\begin{array}{l}84.46 \\
(24.80)\end{array}$ & $\begin{array}{l}83.69 \\
(24.84)\end{array}$ & 0.12 \\
\hline & MICT & $\begin{array}{l}78.39 \\
(20.99)\end{array}$ & $\begin{array}{l}79.69 \\
(13.42)\end{array}$ & 0.16 \\
\hline & UC & $\begin{array}{l}77.29 \\
(10.14)\end{array}$ & $77.11(9.52)$ & 0.84 \\
\hline \multirow[t]{3}{*}{ BMI $\left(\mathrm{kg} / \mathrm{m}^{2}\right)$} & HIIT & $32.08(9.04)$ & $31.80(9.12)$ & 0.15 \\
\hline & MICT & $31.03(8.66)$ & $31.97(5.28)$ & 0.16 \\
\hline & UC & $29.83(2.56)$ & $29.76(2.19)$ & 0.84 \\
\hline \multirow[t]{3}{*}{ Resting HR (BPM) } & HIIT & $71.00(9.04)$ & $67.2(8.85)$ & 0.86 \\
\hline & MICT & $\begin{array}{l}64.00 \\
(20.93)\end{array}$ & $69.45(9.16)$ & $>0.99$ \\
\hline & UC & $\begin{array}{l}72.64 \\
(10.28)\end{array}$ & $\begin{array}{l}69.64 \\
(13.53)\end{array}$ & $>0.99$ \\
\hline \multirow[t]{3}{*}{ VO2 (ml/kg/min) } & HIIT* & $19.00(3.10)$ & $21.9(3.73)$ & 0.0016 \\
\hline & MICT & $18.16(5.99)$ & $21.4(4.09)$ & 0.14 \\
\hline & UC & $19.30(3.92)$ & $19.7(4.40)$ & $>0.99$ \\
\hline \multirow[t]{3}{*}{ VO2 (L/min) } & HIIT* & $1.56(0.33)$ & $1.73(0.40)$ & 0.003 \\
\hline & MICT & $1.46(0.41)$ & $1.63(0.23)$ & 0.14 \\
\hline & UC & $1.48(0.26)$ & $1.49(0.28)$ & 0.83 \\
\hline \multirow[t]{3}{*}{$\begin{array}{l}\text { Resting Systolic Blood Pressure } \\
\text { (mmHg) }\end{array}$} & HIIT & $\begin{array}{l}123.00 \\
(11.77)\end{array}$ & $116.2(7.86)$ & 0.29 \\
\hline & MICT & $\begin{array}{l}118.19 \\
(38.18)\end{array}$ & $\begin{array}{l}122.45 \\
(8.12)\end{array}$ & 0.34 \\
\hline & UC & $\begin{array}{l}120.82 \\
(7.78)\end{array}$ & $\begin{array}{l}118.91 \\
(10.48)\end{array}$ & $>0.99$ \\
\hline \multirow{3}{*}{$\begin{array}{l}\text { Resting Diastolic Blood Pressure } \\
(\mathrm{mmHg})\end{array}$} & HIIT & $77.36(8.90)$ & $77.2(4.02)$ & $>0.99$ \\
\hline & MICT & $\begin{array}{l}73.75 \\
(24.36)\end{array}$ & $79.09(2.88)$ & $>0.99$ \\
\hline & UC & 77.64 (3.98) & 75.27 (3.82) & 0.87 \\
\hline
\end{tabular}


The HIIT group saw a decrease in overall granulocytes (time effect $p=0.05)$, CD 4 T cells (time effect $p=$ 0.01 ), and CD4:CD8 ratio (time effect $p=0.01$; Table 2 ). The MICT group saw an increase in lymphocytes (time effect $p=0.01$; Table 2). MICT had an increase in lymphocytes and CD3 ${ }^{+} \mathrm{T}$ cells after the intervention compared to HIIT (Fig. 1C, 1D). When looking at more mature lymphocyte subsets, only CD4 T cells were decreased in the HIIT group compared to the MICT group (Fig. 1E). No other lymphocyte subsets were different between groups after the intervention. No changes in proportions of these lymphocyte subsets were seen between groups (data not shown). 
Table 2

CD4 T cells are decreased with HIIT training. HIIT caused a decrease in total granulocytes and CD4 T cells, while MICT caused an increase in lymphocytes. Data are presented mean (SD) with bolded pvalues indicating $\mathrm{p}<0.05$.

\begin{tabular}{|c|c|c|c|c|}
\hline Leukocyte Subset & & Pre (cells/ $\mu \mathrm{l}$ WB) & Post (cells/ $\mu$ l WB) & Within Subjects p-value \\
\hline \multirow[t]{3}{*}{ Granulocytes } & HIIT* & $4536.36(1417.76)$ & $3759.09(1365.80)$ & 0.05 \\
\hline & MICT & $4390(800.28)$ & $4105(1154.81)$ & 0.38 \\
\hline & UC & 3640.91 (1457.19) & $3868.18(1996.28)$ & 0.52 \\
\hline \multirow[t]{3}{*}{ Monocytes } & HIIT & $431.82(176.45)$ & $413.64(134.33)$ & 0.62 \\
\hline & MICT & 770 (715.77) & $430(153.12)$ & 0.19 \\
\hline & UC & 450 (159.69) & $427.27(123.21)$ & 0.51 \\
\hline \multirow[t]{3}{*}{ Lymphocytes } & HIIT & $1913.64(320.23)$ & 1822.73 (395.83) & 0.21 \\
\hline & MICT* & 1675 (409.1) & 1865 (484.22) & 0.02 \\
\hline & UC & $1913.64(462.11)$ & $1886.36(281.15)$ & 0.8 \\
\hline \multirow[t]{3}{*}{ NK Cells } & HIIT & 214.81 (86.69) & $241.34(101.59)$ & 0.53 \\
\hline & MICT & 241.07 (63.83) & 298.37 (76.89) & 0.14 \\
\hline & UC & 138.05 (73.82) & $180.03(69.28)$ & 0.12 \\
\hline \multirow[t]{3}{*}{ CD4 T cells } & HIIT* & 716.33 (252.13) & $482.27(191.75)$ & 0.01 \\
\hline & MICT & $566.82(265.99)$ & $659.10(325.2)$ & 0.12 \\
\hline & UC & $694.76(349.47)$ & $608.07(344.74)$ & 0.42 \\
\hline \multirow[t]{3}{*}{ CD8 T cells } & HIIT & 273.99 (158.2) & $256.86(104.44)$ & 0.64 \\
\hline & MICT & $193.26(134.67)$ & $225.14(112.57)$ & 0.27 \\
\hline & UC & $296.01(231.72)$ & $294.86(222.39)$ & 0.98 \\
\hline \multirow[t]{3}{*}{ yठ T cells (CD4-8-) } & HIIT & 85.99 (101.84) & $69.09(62.24)$ & 0.3 \\
\hline & MICT & $33.54(23.49)$ & $29.71(18.25)$ & 0.67 \\
\hline & UC & $56.26(22.82)$ & $59.70(43.38)$ & 0.73 \\
\hline \multirow[t]{3}{*}{ CD4:CD8 } & HIIT* & $3.1(1.25)$ & $2.02(0.68)$ & 0.01 \\
\hline & MICT & $3.83(2.03)$ & $3.22(1.45)$ & 0.32 \\
\hline & UC & $3.79(3.34)$ & $2.74(1.81)$ & 0.38 \\
\hline
\end{tabular}

CD4 Naïve T cells and CD4 Recent Thymic Emigrants are decreased with HIIT training. 
The HIIT group had a decrease in overall CD4 Naïve T cells (time effect $p=0.02$; Table 3), CD4 recent thymic emigrants (RTE; time effect $p=0.01$; Table 3 ). The MICT group had a significant increase in CD $8^{+}$ effector memory $T$ cells (time effect $p=0.03$; Table 3 ). No other effects of time were seen between other differentiated $T$ cell groups within condition. CD 4 Naïve T cells and CD 4 central memory $T$ cells were significantly decreased in the HIIT group compared to the MICT group (Fig. 2A, 2B). There was a trend for an increase in CD8 effector memory T cells in the MICT group compared to HIIT (Fig. 2G). There was a significant decrease in CD4 RTE in the HIIT group compared to the MICT group (Fig. 2I). Of interest, in the exercise groups only (HIIT and MICT combined), there was a trend for a negative relationship between changes in $\mathrm{VO}_{2}$ and changes in CD8 EMRA T-cells ( $r=-0.49, p=0.055$; Fig. 2K). No changes to proportions of these 
Table 3

CD4 Naive T cells and CD4 RTEs are decreased with HIIT training. HIIT caused a decrease in CD4 N T cells and CD4 RTEs only. $\mathrm{N}=$ naïve, $\mathrm{CM}=$ central memory, $\mathrm{EM}=$ effector memory, EMRA = Effector Memory CD45RA ${ }^{+}$.Data are presented mean (SD) with bolded $p$-values indicating $p<0.05$.

\section{T-cell Subset}

CD4

(2)

$\mathrm{CM}$

CD4 Naïve CD31+ (RTE)

Naiive

Pre (cells/ $\mu l$ WB)

\begin{tabular}{llll} 
HIIT* & $264.03(133.13)$ & $163.46(79.56)$ & 0.02 \\
\hline MICT & $148.70(94.68)$ & $178.94(109.27)$ & 0.17 \\
UC & $190.23(97.01)$ & $177.37(131.75)$ & 0.6
\end{tabular}

HIIT*

227.36 (105.46)

MICT

UC

HIIT

MICT

UC

HIIT

EM

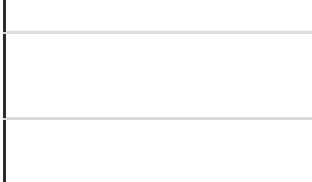

EMRA

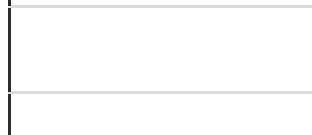

CD8

EMRA

Naive

Naïve

HIIT

(n)

\begin{tabular}{lllll} 
& UC & $109.05(112.75)$ & $114.4(98.08)$ & 0.84 \\
CD8 Naïve CD103+ (RTE) & HIIT & $1.87(1.34)$ & $6.46(10.26)$ & 0.22 \\
& MICT & $1.04(0.43)$ & $0.95(0.49)$ & 0.49 \\
CM & UC & $4.55(4.96)$ & $2.78(3.38)$ & 0.41 \\
& HIIT & $37.31(20.55)$ & $44.46(24.35)$ & 0.6 \\
EM & MICT & $32.69(20.5)$ & $41.93(16.85)$ & 0.19 \\
& UC & $38.94(21.15)$ & $37.56(30.14)$ & 0.91 \\
\hline HIIT & $93.01(49.08)$ & $74.95(31.71)$ & 0.1
\end{tabular}




\begin{tabular}{|c|c|c|c|c|}
\hline T-cell Subset & & Pre (cells/ $\mu \mid$ WB) & Post (cells/ $\mu \mid$ WB) & $p$ \\
\hline & MICT* & $65.78(40.84)$ & $82.29(45.1)$ & 0.03 \\
\hline & UC & $98.29(92.73)$ & $87.16(76.22)$ & 0.57 \\
\hline \multirow[t]{3}{*}{ EMRA } & HIIT & $44.84(40.85)$ & $41.53(45.96)$ & 0.63 \\
\hline & MICT & $24.28(18.12)$ & $23.29(12.44)$ & 0.67 \\
\hline & UC & $49.74(42.38)$ & $55.74(71.31)$ & 0.82 \\
\hline
\end{tabular}


Table 4

$\beta_{2}$-AR expression is not affected by exercise training on lymphocyte subsets. MICT and HIIT did not cause any changes in the expression (MFl; median fluorescence intensity) on lymphocyte subsets and differentiated $\mathrm{T}$ cell subsets. $[\mathrm{CM}=$ central memory, EM = effector memory, EMRA = Effector Memory $\mathrm{CD}_{\left.45 \mathrm{RA}^{+}\right]}$Data are presented mean (SD) with bolded $p$ values indicating $\mathrm{p}<0.05$.

\begin{tabular}{|c|c|c|c|c|c|}
\hline Lymphocyte Subset & & & $\begin{array}{l}\text { Pre ( }(\beta 2-A R \\
\text { MFI) }\end{array}$ & $\begin{array}{l}\text { Post ( } \beta 2-A R \\
\text { MFI) }\end{array}$ & $p$ \\
\hline \multirow[t]{3}{*}{ CD4 $\beta 2-A R+T$ cells } & & HIIT & $20.77(5.22)$ & $23.46(4.87)$ & 0.23 \\
\hline & & MICT & $22.31(7.44)$ & $24.05(4.98)$ & 0.51 \\
\hline & & UC & $18.5(6.92)$ & $20.27(6.07)$ & 0.5 \\
\hline \multirow[t]{12}{*}{$\beta 2-A R+C D 4$} & $\beta 2-A R+$ Naïve & HIIT & $30.11(9.90)$ & 38.38 (15.33) & 0.25 \\
\hline & & MICT & 33.54 (12.99) & $33.36(6.73)$ & 0.97 \\
\hline & & UC & 29.19 (18.33) & $28.99(11.41)$ & 0.97 \\
\hline & $\beta 2-A R+C M$ & HIIT & $22.09(5.24)$ & $25.49(6.56)$ & 0.12 \\
\hline & & MICT & $25.44(7.95)$ & $26.47(4.95)$ & 0.76 \\
\hline & & UC & $19.31(6.33)$ & $21.53(5.27)$ & 0.42 \\
\hline & $\beta 2-A R+E M$ & HIIT & 13.05 (2.99) & $13.79(2.29)$ & 0.41 \\
\hline & & MICT & $13.07(3.25)$ & 15.09 (3.73) & 0.14 \\
\hline & & UC & $12.92(3.67)$ & 13.09 (3.22) & 0.9 \\
\hline & $\begin{array}{l}\beta 2-A R+ \\
\text { EMRA }\end{array}$ & HIIT & $17.78(8.96)$ & $26.48(14.83)$ & 0.24 \\
\hline & & MICT & $15.03(5.12)$ & $25.74(10.15)$ & 0.07 \\
\hline & & UC & $17.02(9.21)$ & $19.54(14.54)$ & 0.65 \\
\hline \multirow[t]{3}{*}{ CD8 $\beta 2-A R+T$ cells } & & HIIT & 28.73 (11.19) & 38.58 (21.61) & 0.19 \\
\hline & & MICT & 36.15 (14.17) & 39.18 (18.32) & 0.66 \\
\hline & & UC & $23.87(13.47)$ & $128.81(10.94)$ & 0.38 \\
\hline \multirow[t]{6}{*}{$\beta 2-A R+C D 8 T$ cells } & $\beta 2-A R$ + Naïve & HIIT & $28.98(11.94)$ & 41.57 (27.75) & 0.23 \\
\hline & & MICT & $34.91(18.50)$ & $35.28(22.56)$ & 0.96 \\
\hline & & UC & $27.4(20.74)$ & $30.11(16.36)$ & 0.69 \\
\hline & $B 2-A R+C M$ & HIIT & $52.62(18.98)$ & $67.57(27.14)$ & 0.13 \\
\hline & & MICT & $74.54(33.51)$ & $86.42(45.42)$ & 0.57 \\
\hline & & UC & $43.86(21.31)$ & $49.47(22.42)$ & 0.5 \\
\hline
\end{tabular}




\begin{tabular}{|c|c|c|c|c|c|}
\hline \multicolumn{3}{|l|}{ Lymphocyte Subset } & \multirow{2}{*}{$\begin{array}{l}\text { Pre ( } \beta 2 \text {-AR } \\
\text { MFI) } \\
13.96(4.2)\end{array}$} & \multirow{2}{*}{$\begin{array}{l}\text { Post ( } \beta 2-A R \\
\text { MFI) } \\
17.80(6.54)\end{array}$} & \multirow{2}{*}{$\begin{array}{l}p \\
0.2\end{array}$} \\
\hline & $\beta 2-A R+E M$ & HIIT & & & \\
\hline & & MICT & $18.11(7.14)$ & $16.92(4.78)$ & 0.74 \\
\hline & & UC & $14.07(2.65)$ & $15.76(4.75)$ & 0.42 \\
\hline & $\begin{array}{l}\beta 2-A R+ \\
\text { EMRA }\end{array}$ & HIIT & $22.71(13.02)$ & $15.88(6.1)$ & 0.21 \\
\hline & & MICT & 18.20 (11.77) & 21.75 (12.91) & 0.07 \\
\hline & & UC & $16.72(7.13)$ & 12.85 (5.59) & 0.27 \\
\hline \multirow{3}{*}{ 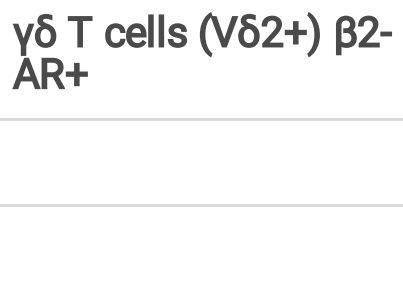 } & & HIIT & $13.63(12.05)$ & $17.58(11.38)$ & 0.42 \\
\hline & & MICT & $4.67(8.83)$ & $11.73(6.4)$ & 0.11 \\
\hline & & UC & $8.95(8.51)$ & $10.45(6.71)$ & 0.7 \\
\hline \multirow[t]{3}{*}{ NK Cells $\beta 2$-AR+ } & & HIIT & 36.29 (11.54) & 34.89 (7.69) & 0.78 \\
\hline & & MICT & $33.38(9.22)$ & $21.51(6.37)$ & 0.51 \\
\hline & & UC & $30.30(9.23)$ & $30.08(7.61)$ & 0.91 \\
\hline
\end{tabular}

cellular populations were found (data not shown). The level of $\beta 2-A R$ (median fluorescence intensity; MFI) was measured on lymphocyte subsets before and after exercise training. There were no changes to the B2-AR expression on lymphocyte subsets due to exercise training (Table 4).

Plasma circulating myokines are related to changes in lymphocyte subset changes and $\beta 2-A R$ expression on lymphocytes.

No changes were observed between groups for levels of circulating myokines IL-7, IL-1, IL-6, and osteonectin (supplementary Fig. 1) [27]. Of note, there was a trend for a difference between the HIIT and UC groups in changes of IL-7 $(p=0.14)$. Changes in plasma osteonectin were negatively related to changes in CD 4 naïve T cells in the HIIT group only ( $r=-0.79$; Fig. 3A); and changes in IL- 6 were negatively related to changes in CD4 T-cells in the HIIT group only ( $r=-0.77$, Fig. 3B). Changes in plasma IL-15 were postively related to changes in the number of circulating CD4 EM T cells in the HIIT group only $(r=0.84$; Fig. $3 C$ ) and negatively related to changes in the number of circulating CD8 EMRA T cells in the MICT group only ( $r=-0.90 ;$ Fig. 3D). Changes in plasma osteonectin were negatively related to changes in the $\beta 2-$ AR expression (median fluorescence intensity; MFI) on CD8 EM T cells in the MICT group only ( $r=-0.87$; Fig. 3E) and positively related to changes in the $\beta 2$-AR expression on NK cells in the MICT group only ( $r=$ 0.82 ; Fig. 3F). Changes in IL-7 were found to be positively related to changes in $\beta 2-A R$ expressing CD4 T cells $(r=0.58$; Fig. $3 G), \beta 2-A R$ expressing CD 4 naive $T$ cells $(r=0.59$; Fig. $3 F)$ in the exercise groups (HIIT + MICT) only. 


\section{Changes in $\mathrm{VO}_{2 \max }$ are positively correlated with $\beta 2$-AR MFI expression on T-cell subsets}

When combining the HIIT and MICT groups together and comparing to changes in fitness, there were trends for a positive relationship between the $\triangle \beta 2$-AR MFI on CD4 CM T-cells ( $r=0.72$, Fig. 4A). Furthermore, this positive relationship was significant on CD8 CM T-cell $\triangle \beta 2$-AR MFI expression $(r=0.58$, Fig. 4B). Similar relationships were seen in the parent T-cell populations, with a positive trending relationship between the changes in fitness and the $\triangle \beta 2$-AR MFI expression on CD4 T cells $(r=0.48, p=$ 0.05 , Fig. $4 C$ ) and $\triangle \beta 2$-AR MFI expression on CD8 T-cells $(r=0.51, p=0.05$, Fig. 4D). The UC group had negative relationships compared to the exercise groups (data not shown).

\section{Discussion}

The aim of this study was to determine the effects of supervised aerobic exercise training and to compare two forms of exercise prescription (HIIT or MICT) on peripheral T-cell subsets indicative of immunosenescence in a population of older women at high risk of developing breast cancer. The main findings from this study were: 1) HIIT decreased total granulocytes, total CD4 + T-cells, CD4 + naïve T-cells, CD4 + RTE and the CD4:CD8 ratio after 12-weeks training, whereas MICT increased total lymphocytes and CD8 EM T-cells; 2) The change in number of total T-cells, CD4 + naïve T-cells, CD4 + CM T-cells and CD4 + RTE was elevated after MICT compared to HIIT; and 3) changes in $\mathrm{VO}_{2 \mathrm{max}}$ after training, regardless of exercise prescription, was positively related to changes in $\beta 2-A R$ expression on $C M$ subsets of both $C D 4+$ and CD8 + T-cells, and tended to be negatively related to the change in CD8 + EMRA T-cells.

Immunosenescence may increase the risk of developing age-related diseases such as cancer [11]. Changes in the composition of peripheral T-cells are hallmark features of immunosenescence, with 'older looking' T-cell compartments (e.g. lower CD4:CD8 T-cell ratios, increased CD8 EMRA T-cells, and fewer naïve and RTE subsets of CD $4+$ and CD $8+T$-cells) being predictive of poor immune responses to vaccination and all-cause mortality in older adults [28]. T-cell profiles associated with immunosenescence were identified in women recently diagnosed with breast cancer and there is emerging evidence that immunosenescence could precipitate cancer occurrence [29,30]. Exercise is known to increase immune function over the lifespan and concomitantly reduce cancer risk, particularly breast, prostate, colorectal and lung cancer $[22,31]$. While cross-sectional studies have provided evidence that exercise can mitigate age-related changes in the peripheral T-cell compartment $[5,19,19,21,22]$, longitudinal studies are required for us to know if exercise can help rejuvenate an already acquired 'older looking' T-cell profile. For the first time, we show here that MICT, but not HIIT, positively alters the peripheral T-cell compartment toward a less senescent phenotype. After training, the change in numbers of total T-cells, CD4 + naïve Tcells, CD 4 + CM T-cells and CD4 + RTE were elevated after MICT compared to HIIT. Remarkably, MICT and HIIT tended to evoke divergent effects on the peripheral T-cell pool, with those T-cell subtypes found to increase or be maintained after MICT had conversely decreased after HIIT. The finding that MICT but not HIIT increased the frequency of CD8 + EM cells in circulation could have important implications for anti- 
tumor immune surveillance as these are the CD $8+T$-cell subsets that predominantly infiltrate human breast tumors [32].

Exercise interventions involving HIIT have been preferred over MICT due to the lower time commitment and comparable improvements in cardiorespiratory fitness and biomarkers of inflammation [33, 34]. However, the present findings indicate that HIIT may not be an effective form of exercise training to evoke positive changes in the frequency of the peripheral T-cell compartment as they relate to markers of immunosenescence and could actually promote a pro-senescent phenotype. For instance, HIIT reduced naïve CD 4 + T-cell numbers by 38\% whereas MICT tended to increase naïve CD 4 + T-cells by $20 \%$. Although IL-7 is known to promote thymic mass and correlates with the frequency of peripheral naïve Tcells and RTEs [35, 36], we surprisingly found no relationships between changes in serum IL-7 and RTEs despite observing a trend for serum IL-7 levels to drop after HIIT but not MICT training. We did find, however, that changes in IL-7 were positively related with changes in the number of circulating CD4 and CD4 naïve T cells expressing the $\beta_{2}-A R$ in both treatment groups (HIIT + MICT) but not the controls. It has been shown in mice that the $\beta_{2}$-AR binds norepinephrine to generate Th1 cells that produce 2 - to 4 -fold more IFN-y during an immune response [37]. It is possible, therefore, that IL-7 levels regulated by exercise can influence the generation of naïve CD $4+$ T-cells that are capable of differentiating into Th1 T-cells via norepinephrine but this requires further investigation. Additionally, HIIT reduced the total number of circulating granulocytes to near significant $(p=0.05)$ levels whereas MICT did not, indicating a potentially greater anti-inflammatory response promoted by HIIT over MICT. Indeed, a recent pilot study reported improvements in neutrophil function after 10-weeks of HIIT in older adults identified as high risk of developing type 2 diabetes, although this study did not compare HIIT to MICT [38]. Collectively, these data underscore the importance of exercise, mode, intensity, duration and volume when it comes to prescribing exercise for immune and anti-inflammatory benefits in older adults, and in people at high risk of disease.

Although neither MICT or HIIT significantly altered the number of CD8 EMRA T-cells, we did find a near significant inverse relationship between the changes in absolute $\mathrm{VO}_{2 \max }(\mathrm{ml} / \mathrm{min})$ and number of $\mathrm{CD} 8+$ EMRA T-cells $(p=0.055)$. We previously reported inverse relationships between $\mathrm{VO}_{2 \text { max }}$ and highly differentiated (e.g. KLRG1+/CD28-/CD57+) CD8 + T-cells associated with immunosenescence in healthy men [39]. These cross-sectional findings have been corroborated by other groups, in addition to the observation that $\mathrm{VO}_{2 \max }$ is positively associated with the composition of naïve $\mathrm{CD} 4+$ and $\mathrm{CD} 8+\mathrm{T}$-cells and RTEs in peripheral blood $[19,35]$. Collectively, these findings indicate that an exercise training program may have to evoke discernible changes in aerobic fitness to reduce the frequency of late-stage differentiated T-cells from the periphery. A recent study reported a decrease in 'senescent' CD57 + CD8 + Tcells and an increase in naïve CD8 + T-cells in peripheral blood following 6-weeks strength endurance training in older women seropositive to cytomegalovirus [40]. The positive shifts in T-cell frequency reported here and by Dinh et al., bolstered by previous randomized controlled trials showing increased immune responses to vaccination after a period of exercise training [41, 42], provide robust evidence that exercise training is capable of rejuvenating an already acquired senescent phenotype to evoke meaningful changes in overall immune function. Moreover, while evidence is beginning to show that 
patients newly diagnosed with cancer have immunosenescent profiles and that exercise can extend survival during treatment for breast cancer and other solid tumors [43, 44], whether these exerciseinduced changes in the frequency of T-cell subsets indicative of immunosenescence can lower the risk of developing breast cancer remains to be determined. A recent long-term follow up study of $>50,000$ women found no relationship between circulating numbers of CD4 + or CD8 + T-cells and risk of developing breast cancer [45], although it is important to note that this study did not consider T-cell subset composition (e.g. naïve, CM, EM and EMRA) or functionality, which can be altered considerably without greatly affecting total CD4 + or CD8 + T-cell numbers [46-49]. It will also be important to consider how exercise-induced shifts in T-cell subsets can influence prognosis in breast cancer patients on active treatment and at different stages of disease. For instance, in patients with metastatic breast cancer, a higher frequency of circulating naïve CD $4+$ and CD $8+T$-cells is associated with poorer prognosis in patients treated with high-dose paclitaxel but not cyclophosphamide containing regimens [50], while higher numbers of late-stage differentiated CD8 + T-cells have been associated with shorter progressionfree survival and overall survival $[30,51]$.

The mechanisms by which exercise training can alter the composition of the peripheral T-cell compartment have not been fully determined. Exercise may limit the age-related expansion of late-stage differentiated T-cells by helping to exert better control over latent viral infections (e.g. CMV), or by progressively removing these cells by increasing their exposure to pro-apoptotic stimuli over time $[39,52]$. Increased apoptosis of late-stage differentiated T-cells by exercise has been hypothesized to promote the mobilization of 'new recruits', facilitated by an increase hematopoiesis and muscle-derived cytokines, such as IL-7, that can promote maintenance of thymic mass and increase production and development of naïve T-cells [21]. As previous studies found positive associations between the levels of muscle-derived cytokines such as IL-7 and IL-15 in plasma with the numbers of naïve and RTE T-cells in the blood of older endurance trained athletes $[1,19,53]$, we investigated here whether changes in T-cell frequency were associated with changes in the levels of circulating IL-7, IL-15, IL-6, and ostenectin after the 12-week training intervention. IL-15 is an important myokine for optimal memory T-cell responses [54], increases Tcell antitumor immunity [55], and general T-cell activation and function [56], and has been shown to be highly expressed in muscle [57]. IL-6, on the other hand, is thought to be an overall pro-inflammatory cytokine [58] responsible for increasing chronic morbidity and aging [59], but its release from skeletal muscle during exercise plays an anti-inflammatory role [60] and has also been shown to facilitate tumor infiltration of exercise-mobilized NK-cells [61-63]. Osteonectin is a myokine that has been shown to inhibit tumorigenesis in colon cancer and to also potentially play a role in repairing damaged skeletal muscle [64]. Here, we found that the change in CD4 T-cells and CD4 N T-cells were negatively related to changes in IL- 6 and osteonectin after HIIT but not MICT, indicating a potential role for osteonectin and IL6 in the maintenance of peripheral naïve T-cells in response to exercise training. We also found that changes in CD8 EMRA T-cells were inversely correlated with serum IL-15 levels for the MICT but not the HIIT group. More research is needed to identify potential causative roles for these myokines in regulating the peripheral T-cell compartment after exercise training. 
The $\beta 2$-AR has been shown to play an important role in the activation, mobilization and redistribution of immune cells with an increased ability to infiltrate tumors in response to exercise. In murine models of cancer, exercise has been shown to promote CD8 + T-cell and NK-cell infiltration to tumors and suppression of tumor growth via a catecholamine and $\beta 2$-AR dependent mechanism $[63,65,66]$. Potential increases in $\beta 2$-AR expression with exercise training might help contribute to a more effective anti-tumor response. While neither MICT or HIIT affected $\beta 2$-AR expression, we did find a positive association between the changes in absolute VO2max and $\beta 2$-AR expression on the surface of central memory subsets of both CD8 + and CD4 + T-cells. There was also a trend for a positive relationship between the changes in $\beta 2-A R$ expression on CD8 $+C M$ T cells and plasma osteonectin levels. The $\beta 2-A R$ has also been shown to modulate memory CD8 T-cell function [67], making the $\beta 2-A R$ a potential target in mediating aging related immunosenescence via exercise training.

Despite this being the first randomized controlled trial to show that an aerobic exercise training intervention can positively alter the frequency of T-cell subsets indicative of immunosenescence in a population of older women at high risk of developing breast cancer, we do acknowledge several limitations. These include the small sample size, lack of an endpoint measure of global immune competency (e.g. systemic challenge with a vaccine or experimental antigen), and the correlative nature of several of our findings. We also did not control for dietary intake and focused solely on a population of women at high risk for breast cancer who were living with overweight/obesity. As adiposity is known to influence immune cell function and phenotype [68-71], our interpretations of these findings must be taken with caution when applied to the lean older adult population.

\section{Conclusion}

Aerobic exercise training is capable of altering the frequency of peripheral T-cells associated with immunosenescence in older women at high risk of breast cancer with divergent effects seen for MICT versus HIIT. Increases in $\mathrm{VO}_{2 \text { peak }}$ after training, regardless of exercise prescription, are associated with an increase in $\beta 2-A R$ expression on CM subsets of CD $4+$ and $C D 8+T$-cells and a reduced frequency of EMRA CD8 + T-cells. Further study is required to identify the mechanisms underlying the opposing effects of HIIT and MICT on the frequency of peripheral T-cells, their relationships with circulating myokines, and to determine if exercise-induced changes in immunity can alter the risk of developing breast cancer.

\section{Materials And Methods}

Study Design, Participants, Recruitment and Intervention Procedures

This was a parallel group, randomized controlled trial that consisted of a 12-week supervised exercise training intervention. Study groups consisted of HIIT $(n=8)$, MICT $(n=8)$, and UC $(n=8)$. This investigation was approved by the University of Texas MD Anderson Cancer Center Institutional Review Board. Details regarding eligibility criteria, recruitment and intervention procedures are reported elsewhere $[27,72]$. 
Eligible participants were post-menopausal women who were overweight or obese, as defined by body mass index ( $\geq 25 \mathrm{~kg} / \mathrm{m}^{2}$ ), who were considered at heightened risk of developing breast cancer due to an elevated Gail 5-year risk score $(>1.66 \%)$, lifetime risk score $(>20 \%)$, history of ductal or lobular atypia, or history of ductal or lobular carcinoma in situ (non-invasive breast cancer). Participants were recruited from the University of Texas MD Anderson Cancer Center, Clinical Cancer Prevention Center.

Participants assigned to HIIT and MICT presented at the Cancer Prevention Center three times per week and completed supervised treadmill exercise, as previously described [27]. Briefly, HIIT consisted of a 5minute warm-up, four 4-minute high-intensity intervals, followed by a 3-minute active recovery interval for 33 minutes. The MICT workout was 41 minutes in length, ensuring HR stayed consistent during the whole session. Participants assigned to UC received educational material related to healthful diet and exercise habits at baseline, and monthly phone calls by study personnel pertaining to their healthy lifestyle goals. More thorough descriptions can be found in previous literature [27, 72]

Assessment Procedures

Assessment sessions, including fitness testing, were conducted at baseline, 6-weeks and upon completion of the 12-week intervention (end-of-study). Procedures are described in detail elsewhere [27, 72]. Relevant to the present investigation, fasting whole blood was collected at baseline and end-of-study using standard phlebotomy procedures.

Blood samples were collected and processed according to previous reports [39, 73]. Briefly, peripheral blood mononuclear cells (PBMCs) were isolated by density centrifugation (Histo-paque; Sigma) and frozen at $-80 * \mathrm{C}$ until further analysis. Upon thawing, cells were washed twice with phosphate buffered saline (PBS; Sigma) and stained with the following antibodies: TCR-Vd2 (FITC, Miltenyi Biotec) CD3 VioGreen, Miltenyi Biotec; Clone: REA613), ADRB2 (primary antibody Abnova; clone: 4A6C9; linked with lightning-link APC Labeling Kit,Expedeon), CD8 (VioBlue, Miltenyi Biotec; clone: BW135/80), CD4 (FITC, Miltenyi Biotec; clone: REA623; or PE-Cy5.5; ebioscience; clone:SK3), CD56 (APC-Vio 770; Miltenyi Biotec; Clone: REA196), CD20 PerCP-Vio 700; Miltenyi Biotec; clone: REA780), CD62L (PE, Miltenyi Biotec; clone: REA615), CD45RA (PE-Vio 770; clone: T6D11), CD45 (APC; Miltenyi Biotec; Clone: REA747), CD103 (APC, Miltenyi Biotec), CD31 (PerCP-Vio 770; Miltenyi Biotec; clone: REA730). Samples were stained at room temperature in the dark for 30 minutes. Samples were then washed and quantified via flow cytometry (MacsQuant, Miltenyi). Analysis of flow cytometric data was performed on FlowLogic (v7).

Fold changes were calculated as (Post-Pre)/Pre. Non normally distributed sets were $\log _{10}$ transformed and once again assess for normal distribution. Once fold changes were calculated, one-way ANOVA tests were conducted between HIIT, MICT, and UC groups for each cellular population. Pearson's correlations were conducted. All statistical tests were conducted on GraphPad Prism (v8). P $<0.05$ was considered statistically significant. Statistical tests with $p<0.1$ are reported as trends. Data are presented as Mean+/SD. 


\section{Declarations}

\section{Funding}

This study was funded by the NCI R25 Cancer Prevention Research Training Program (CA057730, PI:

Shine Chang PhD), the MD Anderson Cancer Center/Energy Balance Assessment Supplemental Funding (PI: Susan Gilchrist MD), the MD Anderson Cancer Center, Center for Energy Balance in Cancer Prevention and Survivorship. GMN was funded by Cancer Biology Training Grant T32CA009213 and the Interdisciplinary Training in Cardiovascular Research Training Grant T32HL007249.

\section{Acknowledgments}

We would like to acknowledge all of our participants for taking part in the study. We would also like to thank all the individuals who helped our participants complete the exercise sessions at AIM (MD Anderson shared resource) and MD Anderson's Cancer Prevention Center.

\section{Authors' contributions}

RJS, SG, and AMC designed the study. AMC carried out the intervention. AMC and SG conducted assessment sessions. GMN, NHA, FLB and PLM analyzed the data. GMN and RJS wrote the manuscript. All authors contributed to the writing and data interpretation and approved the final version of the manuscript before submission.

\section{Institutional Review Board Statement}

This investigation was approved by the University of Texas MD Anderson Cancer Center Institutional Review Board (IRB: 2016-0442) and within the 1964 Helsinki declaration and its later amendments or comparable ethical standards. All participants provided written informed consent prior to participation.

\section{Informed Consent Statement}

All participants provided written informed consent prior to participation.

\section{Data Availability Statement}

The data are available from the corresponding author on reasonable request.

\section{Conflicts of Interest}

All authors declare no competing interests.

\section{References}

1. Duggal NA, Niemiro G, Harridge SDR, Simpson RJ, Lord JM. Can Physical Activity Ameliorate Immunosenescence and Thereby Reduce Age-Related Multi-Morbidity? Nat Rev Immunol. 2019. 
doi:10.1038/s41577-019-0177-9.

2. Weinberger B, Lazuardi L, Weiskirchner I, Keller M, Neuner C, Fischer K-H, Neuman B, Würzner R, Grubeck-Loebenstein B. Healthy Aging and Latent Infection with CMV Lead to Distinct Changes in CD8 + and CD4 + T-Cell Subsets in the Elderly. Hum Immunol. 2007;68:86-90. doi:10.1016/j.humimm.2006.10.019.

3. Le Page A, Dupuis G, Larbi A, Witkowski JM, Fülöp T. Signal Transduction Changes in CD4 + and CD8 + T Cell Subpopulations with Aging. Exp Gerontol. 2018;105:128-39. doi:10.1016/j.exger.2018.01.005.

4. Goronzy JJ, Weyand CM, Successful, Maladaptive T, Cell. Aging Immunity. 2017;46:364-78. doi:10.1016/j.immuni.2017.03.010.

5. Goronzy JJ, Fang F, Cavanagh MM, Qi Q, Weyand CM. Naive T Cell Maintenance and Function in Human Aging. J Immunol. 2015;194:4073-80. doi:10.4049/jimmunol.1500046.

6. Crooke SN, Ovsyannikova IG, Poland GA, Kennedy RB. Immunosenescence and Human Vaccine Immune Responses. Immun Ageing 2019, 16, doi:10.1186/s12979-019-0164-9.

7. Elyahu Y, Hekselman I, Eizenberg-Magar I, Berner O, Strominger I, Schiller M, Mittal K, Nemirovsky A, Eremenko E, Vital A, et al. Aging Promotes Reorganization of the CD4 T Cell Landscape toward Extreme Regulatory and Effector Phenotypes. Sci Adv 2019, 5, doi:10.1126/sciadv.aaw8330.

8. Wikby A, Johansson B, Olsson J, Löfgren S, Nilsson B-O, Ferguson F. Expansions of Peripheral Blood CD8 T-Lymphocyte Subpopulations and an Association with Cytomegalovirus Seropositivity in the Elderly: The Swedish NONA Immune Study. Exp Gerontol. 2002;37:445-53. doi:10.1016/S05315565(01)00212-1.

9. Olsson J, Wikby A, Johansson B, Löfgren S, Nilsson B-O, Ferguson FG. Age-Related Change in Peripheral Blood T-Lymphocyte Subpopulations and Cytomegalovirus Infection in the Very Old: The Swedish Longitudinal OCTO Immune Study. Mech Ageing Dev. 2001;121:187-201. doi:10.1016/S0047-6374(00)00210-4.

10. Onyema OO, Decoster L, Njemini R, Forti LN, Bautmans I, De Waele M, Mets T. Chemotherapy-Induced Changes and Immunosenescence of CD8 + T-Cells in Patients with Breast Cancer. Anticancer Res. 2015;35:1481-9.

11. Lian J, Yue Y, Yu W, Zhang Y, Immunosenescence. A Key Player in Cancer Development. J Hematol Oncol. 2020;13:151. doi:10.1186/s13045-020-00986-Z.

12. Campbell JP, Turner JE. Debunking the Myth of Exercise-Induced Immune Suppression: Redefining the Impact of Exercise on Immunological Health Across the Lifespan. Front Immunol. 2018;9:648. doi:10.3389/fimmu.2018.00648.

13. Flynn MG, McFarlin BK, Markofski MM. The Anti-Inflammatory Actions of Exercise Training. Am J Lifestyle Med. 2007;1:220-35. doi:10.1177/1559827607300283.

14. Flynn MG, Markofski MM, Carrillo AE. Elevated Inflammatory Status and Increased Risk of Chronic Disease in Chronological Aging: Inflamm-Aging or Inflamm-Inactivity? Aging Dis. 2019;10:147-56. doi:10.14336/AD.2018.0326. 
15. Kohut ML, Senchina DS. Reversing Age-Associated Immunosenescence via Exercise. Exerc Immunol Rev. 2004;10:6-41.

16. Kohut ML, Thompson JR, Lee W, Cunnick JE. Exercise Training-Induced Adaptations of Immune Response Are Mediated by Beta-Adrenergic Receptors in Aged but Not Young Mice. J Appl Physiol. 2004;96:1312-22. doi:10.1152/japplphysiol.00792.2003.

17. Senchina DS, Kohut ML. Immunological Outcomes of Exercise in Older Adults. Clin Interv Aging. 2007;2:3-16. doi:10.2147/ciia.2007.2.1.3.

18. Ranadive SM, Kappus RM, Cook MD, Yan H, Lane AD, Woods JA, Wilund KR, Iwamoto G, Vanar V, Tandon R, et al. Effect of Acute Moderate Exercise on Induced Inflammation and Arterial Function in Older Adults. Exp Physiol. 2014;99:729-39. doi:10.1113/expphysiol.2013.077636.

19. Duggal NA, Pollock RD, Lazarus NR, Harridge S, Lord JM. Major Features of Immunesenescence, Including Reduced Thymic Output, Are Ameliorated by High Levels of Physical Activity in Adulthood. Aging Cell 2018, 17, doi:10.1111/acel.12750.

20. Simpson RJ, Hussain M, Baker F, Bigley AB, Peek MK, Stowe RP. Cardiorespiratory Fitness Is Associated with Better Control of Latent Herpesvirus Infections in a Large Ethnically Diverse Community Sample: Evidence from the Texas City Stress and Health Study. Brain Behav Immun. 2017;66:e35. doi:10.1016/j.bbi.2017.07.128.

21. Simpson RJ, Aging. Persistent Viral Infections, and Immunosenescence: Can Exercise "Make Space”? Exerc Sport Sci Rev. 2011;39:23-33. doi:10.1097/JES.0b013e318201f39d.

22. Simpson RJ, Lowder TW, Spielmann G, Bigley AB, LaVoy EC, Kunz H. Exercise and the Aging Immune System. Ageing Research Reviews. 2012;11:404-20. doi:10.1016/j.arr.2012.03.003.

23. Minuzzi LG, Rama L, Chupel MU, Rosado F, Dos Santos JV, Simpson R, Martinho A, Paiva A, Teixeira AM. Effects of Lifelong Training on Senescence and Mobilization of T Lymphocytes in Response to Acute Exercise. Exerc Immunol Rev. 2018;24:72-84.

24. Santulli G, laccarino G. Pinpointing Beta Adrenergic Receptor in Ageing Pathophysiology: Victim or Executioner? Evidence from Crime Scenes. Immun Ageing 2013, 10, 10, doi:10.1186/1742-4933-1010.

25. Schutzer WE, Xue H, Reed JF, Mader SL. Effect of Age on Vascular Ss2-Adrenergic Receptor Desensitization Is Not Mediated by the Receptor Coupling to $G$ i Proteins. The Journals of Gerontology Series A: Biological Sciences Medical Sciences. 2006;61:899-906. doi:10.1093/gerona/61.9.899.

26. Weston M, Taylor KL, Batterham AM, Hopkins WG. Effects of Low-Volume High-Intensity Interval Training (HIT) on Fitness in Adults: A Meta-Analysis of Controlled and Non-Controlled Trials. Sports Med. 2014;44:1005-17. doi:10.1007/s40279-014-0180-z.

27. Coletta AM, Agha NH, Baker FL, Niemiro GM, Mylabathula PL, Brewster AM, Bevers TB, FuentesMattei E, Basen-Engquist K, Gilchrist SC, et al. The Impact of High-Intensity Interval Exercise Training on NK-Cell Function and Circulating Myokines for Breast Cancer Prevention among Women at High Risk for Breast Cancer. Breast Cancer Res Treat. 2021. doi:10.1007/s10549-021-06111-z. 
28. Rogers CJ, Zaharoff DA, Hance KW, Perkins SN, Hursting SD, Schlom J, Greiner JW. Exercise Enhances Vaccine-Induced Antigen-Specific T Cell Responses. Vaccine. 2008;26:5407-15. doi:10.1016/j.vaccine.2008.07.081.

29. Turner JE, Brum PC. Does Regular Exercise Counter T Cell Immunosenescence Reducing the Risk of Developing Cancer and Promoting Successful Treatment of Malignancies? Available online: https://www.hindawi.com/journals/omcl/2017/4234765/ (accessed on 18 May 2020).

30. Liu X-R, Yu J-J, Song G-H, Di L-J, Jiang H-F, Yan Y, Liang X, Zhang R-Y, Ran R, Wang J, et al. Peripheral Cytotoxic T Lymphocyte Predicts First-Line Progression Free Survival in HER2-Positive Advanced Breast Cancer. The Breast. 2021;55:7-15. doi:10.1016/j.breast.2020.11.006.

31. Simpson RJ, Kunz H, Agha N, Graff R Chapter Fifteen - Exercise and the Regulation of Immune Functions. In Progress in Molecular Biology and Translational Science; Bouchard, C., Ed.; Molecular and Cellular Regulation of Adaptation to Exercise; Academic Press, 2015; Vol. 135, pp. 355-380.

32. Egelston CA, Avalos C, Tu TY, Simons DL, Jimenez G, Jung JY, Melstrom L, Margolin K, Yim JH, Kruper L, et al. Human Breast Tumor-Infiltrating CD 8 + T Cells Retain Polyfunctionality despite PD-1 Expression. Nat Commun. 2018;9:4297. doi:10.1038/s41467-018-06653-9.

33. Fiorenza M, Gunnarsson TP, Hostrup M, laia FM, Schena F, Pilegaard H, Bangsbo J. Metabolic StressDependent Regulation of the Mitochondrial Biogenic Molecular Response to High-Intensity Exercise in Human Skeletal Muscle. The Journal of Physiology. 2018;596:2823-40. doi:10.1113/JP275972.

34. Bessa A, Oliveira VN, De Agostini GG, Oliveira RJS, Oliveira ACS, White G, Wells G, Teixeira DNS, Espindola FS. Exercise Intensity and Recovery: Biomarkers of Injury, Inflammation and Oxidative Stress. Journal of Strength Conditioning Research 2013, 1, doi:10.1519/JSC.0b013e31828f1ee9.

35. McFarland RD, Douek DC, Koup RA, Picker LJ Identification of a Human Recent Thymic Emigrant Phenotype. Proceedings of the National Academy of Sciences 2000, 97, 4215-4220, doi:10.1073/pnas.070061597.

36. Andrew D, Aspinall R. Age-Associated Thymic Atrophy Is Linked to a Decline in IL-7 Production. Exp Gerontol. 2002;37:455-63. doi:10.1016/S0531-5565(01)00213-3.

37. Swanson MA, Lee WT, Sanders VM. IFN-y Production by Th1 Cells Generated from Naive CD $4{ }^{+}$T Cells Exposed to Norepinephrine. J Immunol. 2001;166:232-40. doi:10.4049/jimmunol.166.1.232.

38. Bartlett DB, Slentz CA, Willis LH, Hoselton A, Huebner JL, Kraus VB, Moss J, Muehlbauer MJ, Spielmann G, Muoio DM, et al. Rejuvenation of Neutrophil Functions in Association With Reduced Diabetes Risk Following Ten Weeks of Low-Volume High Intensity Interval Walking in Older Adults With Prediabetes - A Pilot Study. Front Immunol. 2020;11:729. doi:10.3389/fimmu.2020.00729.

39. Spielmann G, Bollard CM, Bigley AB, Hanley PJ, Blaney JW, LaVoy ECP, Pircher H, Simpson RJ. The Effects of Age and Latent Cytomegalovirus Infection on the Redeployment of CD8 + T Cell Subsets in Response to Acute Exercise in Humans. Brain Behav Immun. 2014;39:142-51. doi:10.1016/j.bbi.2013.05.003.

40. Cao Dinh H, Njemini R, Onyema O0, Beyer I, Liberman K, De Dobbeleer L, Renmans W, Vander Meeren S, Jochmans K, Delaere A, et al. Strength Endurance Training but Not Intensive Strength Training 
Reduces Senescence-Prone T-Cells in Peripheral Blood in Community-Dwelling Elderly Women. $J$ Gerontol A Biol Sci Med Sci, doi:10.1093/gerona/gly229.

41. Woods JA, Keylock KT, Lowder T, Vieira VJ, Zelkovich W, Dumich S, Colantuano K, Lyons K, Leifheit K, Cook M, et al. Cardiovascular Exercise Training Extends Influenza Vaccine Seroprotection in Sedentary Older Adults: The Immune Function Intervention Trial: EXERCISE AND VACCINE RESPONSE IN HEALTHY ELDERLY PEOPLE. J Am Geriatr Soc. 2009;57:2183-91. doi:10.1111/j.15325415.2009.02563.x.

42. Kohut ML, Arntson BA, Lee W, Rozeboom K, Yoon K-J, Cunnick JE, McElhaney J. Moderate Exercise Improves Antibody Response to Influenza Immunization in Older Adults. Vaccine. 2004;22:2298306. doi:10.1016/j.vaccine.2003.11.023.

43. Courneya KS, Segal RJ, Mckenzie DC, Dong H, Gelmon K, Friedenreich CM, Yasui Y, Reid RD, Crawford JJ, Mackey JR. Effects of Exercise during Adjuvant Chemotherapy on Breast Cancer Outcomes. Med Sci Sports Exerc. 2014;46:1744-51. doi:10.1249/MSS.0000000000000297.

44. Courneya KS, Segal RJ, Gelmon K, Mackey JR, Friedenreich CM, Yasui Y, Reid RD, Proulx C, Trinh L, Dolan LB, et al. Predictors of Adherence to Different Types and Doses of Supervised Exercise during Breast Cancer Chemotherapy. Int J Behav Nutr Phys Act. 2014;11:85. doi:10.1186/s12966-014-00850 .

45. Kresovich JK, O'Brien KM, Xu Z, Weinberg CR, Sandler DP, Taylor JA. Prediagnostic Immune Cell Profiles and Breast Cancer. JAMA Netw Open. 2020;3:e1919536. doi:10.1001/jamanetworkopen.2019.19536.

46. Moro-García MA, Alonso-Arias R, Lopez-Larrea C. When Aging Reaches CD4 + T-Cells: Phenotypic and Functional Changes. Front Immunol 2013, 4, doi:10.3389/fimmu.2013.00107.

47. Callender LA, Carroll EC, Beal RWJ, Chambers ES, Nourshargh S, Akbar AN, Henson SM. Human CD8 + EMRA T Cells Display a Senescence-associated Secretory Phenotype Regulated by P38 MAPK. Aging Cell 2018, 17, doi:10.1111/acel.12675.

48. Ferrando-Martínez S, Ruiz-Mateos E, Hernández A, Gutiérrez E, Rodríguez-Méndez M, del M; Ordoñez, Leal A. M. Age-Related Deregulation of Naive T Cell Homeostasis in Elderly Humans. Age (Dordr). 2011;33:197-207. doi:10.1007/s11357-010-9170-8.

49. Goronzy JJ, Lee W-W, Weyand CM, Aging, Diversity T-Cell. Exp Gerontol. 2007;42:400-6. doi:10.1016/j.exger.2006.11.016.

50. Lafrenie RM, Speigl L, Buckner CA, Pawelec G, Conlon MS, Shipp C. Frequency of Immune Cell Subtypes in Peripheral Blood Correlates With Outcome for Patients With Metastatic Breast Cancer Treated With High-Dose Chemotherapy. Clin Breast Cancer. 2019;19:433-42. doi:10.1016/j.clbc.2019.05.002.

51. Song Q, Ren J, Zhou X, Wang X, Song G, Hobeika A, Yuan Y, Lyerly HK. Circulating CD8 + CD28Suppressor T Cells Tied to Poorer Prognosis among Metastatic Breast Cancer Patients Receiving Adoptive T-Cell Therapy: A Cohort Study. Cytotherapy. 2018;20:126-33. doi:10.1016/j.jcyt.2017.08.018. 
52. Simpson RJ, Bigley AB, Spielmann G, LaVoy ECP, Kunz H, Bollard CM. Human Cytomegalovirus Infection and the Immune Response to Exercise. 2016, 19.

53. Bartlett DB, Fox O, McNulty CL, Greenwood HL, Murphy L, Sapey E, Goodman M, Crabtree N, Thøgersen-Ntoumani C, Fisher JP, et al. Habitual Physical Activity Is Associated with the Maintenance of Neutrophil Migratory Dynamics in Healthy Older Adults. Brain Behav Immun. 2016;56:12-20. doi:10.1016/j.bbi.2016.02.024.

54. Richer MJ, Pewe LL, Hancox LS, Hartwig SM, Varga SM, Harty JT. Inflammatory IL-15 Is Required for Optimal Memory T Cell Responses. Journal of Clinical Investigation. 2015;125:3477-90. doi:10.1172/JCl81261.

55. Hurton LV, Singh H, Najjar AM, Switzer KC, Mi T, Maiti S, Olivares S, Rabinovich B, Huls H, Forget M-A, et al. Tethered IL-15 Augments Antitumor Activity and Promotes a Stem-Cell Memory Subset in Tumor-Specific T Cells. Proc Natl Acad Sci USA. 2016;113:E7788-97. doi:10.1073/pnas.1610544113.

56. Schluns KS, Anthony S Emerging Roles for IL-15 in the Activation and Function of T-Cells during Immune Stimulation. RRB 2015, 25, doi:10.2147/RRB.S57685.

57. Ficek K, Ci囚szczyk P, Leźnicka K, Kaczmarczyk M, Leońska-Duniec A. Novel Associations Between Interleukin-15 Polymorphisms and Post-Training Changes of Body Composition Parameters in Young Nonobese Women. Front Physiol. 2019;10:876. doi:10.3389/fphys.2019.00876.

58. Hunter CA, Jones SA. IL- 6 as a Keystone Cytokine in Health and Disease. Nat Immunol. 2015;16:448-57. doi:10.1038/ni.3153.

59. Maggio M, Guralnik JM, Longo DL, Ferrucci L. Interleukin-6 in Aging and Chronic Disease: A Magnificent Pathway. J Gerontol A Biol Sci Med Sci. 2006;61:575-84. doi:10.1093/gerona/61.6.575.

60. Petersen AMW, Pedersen BK. The Role of IL-6 in Mediating the Anti-Inflammatory Effects of Exercise. J Physiol Pharmacol. 2006;57(Suppl 10):43-51.

61. Pedersen BK, Febbraio MA. Muscle as an Endocrine Organ: Focus on Muscle-Derived Interleukin-6. Physiol Rev. 2008;88:1379-406. doi:10.1152/physrev.90100.2007.

62. Toth KG, McKay BR, Lisio MD, Little JP, Tarnopolsky MA, Parise G. IL-6 Induced STAT3 Signalling Is Associated with the Proliferation of Human Muscle Satellite Cells Following Acute Muscle Damage. PLOS ONE. 2011;6:e17392. doi:10.1371/journal.pone.0017392.

63. Pedersen L, Idorn M, Olofsson GH, Lauenborg B, Nookaew I, Hansen RH, Johannesen HH, Becker JC, Pedersen KS, Dethlefsen C, et al. Voluntary Running Suppresses Tumor Growth through Epinephrineand IL-6-Dependent NK Cell Mobilization and Redistribution. Cell Metab. 2016;23:554-62. doi:10.1016/j.cmet.2016.01.011.

64. Lee JH, Jun H-S. Role of Myokines in Regulating Skeletal Muscle Mass and Function. Front Physiol 2019, 10, 42, doi:10.3389/fphys.2019.00042.

65. Kokolus KM, Capitano ML, Lee C-T, Eng JW-L, Waight JD, Hylander BL, Sexton S, Hong C-C, Gordon $\mathrm{CJ}$, Abrams SI, et al. Baseline Tumor Growth and Immune Control in Laboratory Mice Are 
Significantly Influenced by Subthermoneutral Housing Temperature. Proceedings of the National Academy of Sciences 2013, 110, 20176-20181, doi:10.1073/pnas.1304291110.

66. Qiao G, Bucsek MJ, Winder NM, Chen M, Giridharan T, Olejniczak SH, Hylander BL, Repasky EA. $\beta$ Adrenergic Signaling Blocks Murine CD8 + T-Cell Metabolic Reprogramming during Activation: A Mechanism for Immunosuppression by Adrenergic Stress. Cancer Immunol Immunother. 2019;68:11-22. doi:10.1007/s00262-018-2243-8.

67. Slota C, Shi A, Chen G, Bevans M, Weng N. Norepinephrine Preferentially Modulates Memory CD8 T Cell Function Inducing Inflammatory Cytokine Production and Reducing Proliferation in Response to Activation. Brain Behav Immun. 2015;46:168-79. doi:10.1016/j.bbi.2015.01.015.

68. Asghar A, Sheikh N. Role of Immune Cells in Obesity Induced Low Grade Inflammation and Insulin Resistance. Cellular Immunology, doi:10.1016/j.cellimm.2017.03.001.

69. de Heredia FP, Gómez-Martínez S, Marcos A, Obesity, Inflammation and the Immune System. Proceedings of the Nutrition Society 2012, 71, 332-338, doi:10.1017/S0029665112000092.

70. Hotamisligil GS. Inflammation and Metabolic Disorders. Nature. 2006;444:860-7. doi:10.1038/nature05485.

71. Richard C, Wadowski M, Goruk S, Cameron L, Sharma AM, Field CJ. Individuals with Obesity and Type 2 Diabetes Have Additional Immune Dysfunction Compared with Obese Individuals Who Are Metabolically Healthy. BMJ Open Diabetes Research Care. 2017;5:e000379. doi:10.1136/bmjdrc2016-000379.

72. COLETTA AM, BREWSTER AM, CHEN M, LI Y, BEVERS TB, BASEN-ENGQUIST K, GILCHRIST SC. HighIntensity Interval Training Is Feasible in Women at High Risk for Breast Cancer. Med Sci Sports Exerc. 2019;51:2193-200. doi:10.1249/MSS.0000000000002048.

73. Graff RM, Kunz HE, Agha NH, Baker FL, Laughlin M, Bigley AB, Markofski MM, LaVoy EC, Katsanis E, Bond RA, et al. B2-Adrenergic Receptor Signaling Mediates the Preferential Mobilization of Differentiated Subsets of CD8 + T-Cells, NK-Cells and Non-Classical Monocytes in Response to Acute Exercise in Humans. Brain Behav Immun. 2018;74:143-53. doi:10.1016/j.bbi.2018.08.017.

\section{Supplementary}

Supplementary Info Figure 1 is not available with this version.

\section{Figures}


A

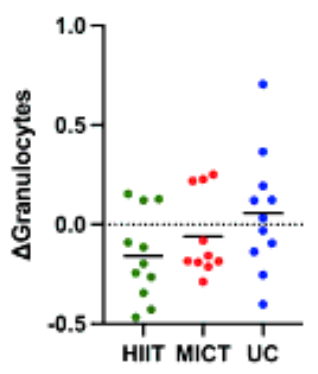

E

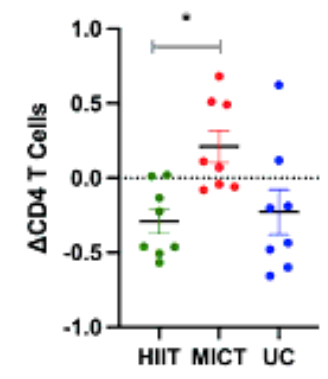

B

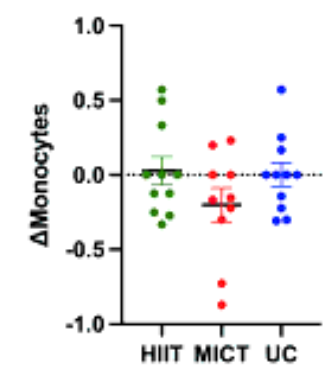

F

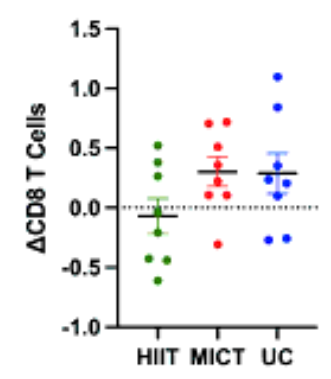

C

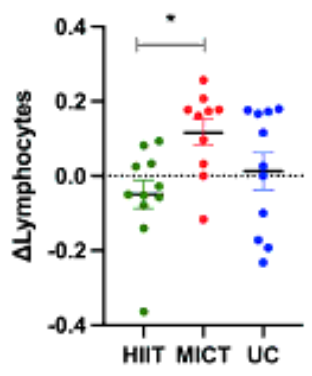

G

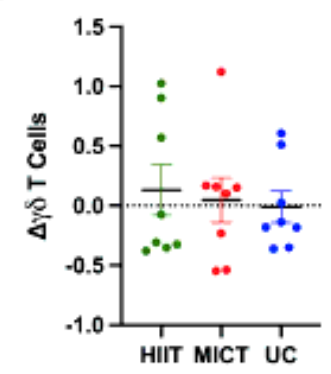

D

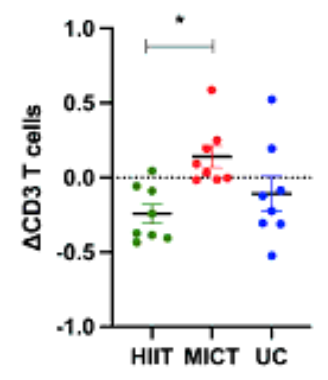

H

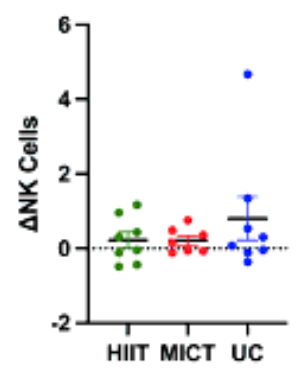

\section{Figure 1}

Lymphocytes, CD3 T cells, and CD 4 T cells are increased with MICT compared to HIIT. Between group comparisons of fold changes for leukocyte subsets before and after exercise training in older women. (A) Granulocytes , (B) Monocytes, and (C) Lymphocytes are depicted. (D) Total CD3 T cells are depicted. (E) Y $\otimes T$ cells, (F) Total CD4 T cells, (G) Total CD8 T cells, and (H) Total NK cells are depicted. Data are presented mean with ${ }^{*} p<0.05$. 
A

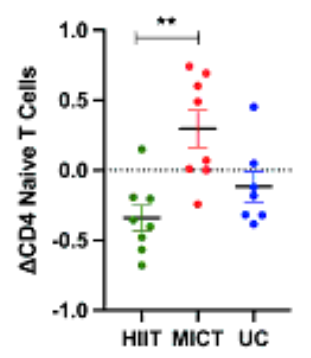

E

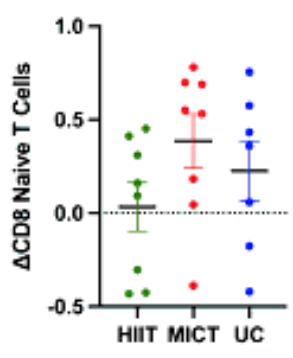

I

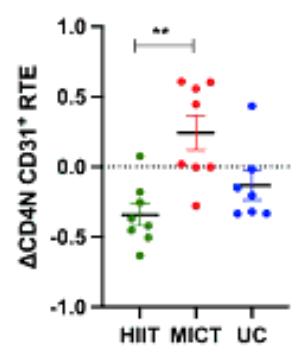

B

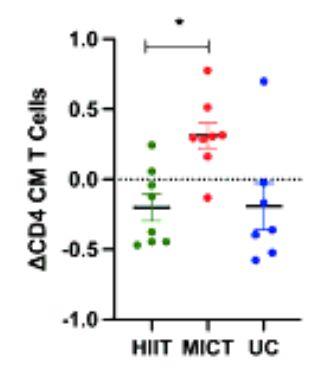

F

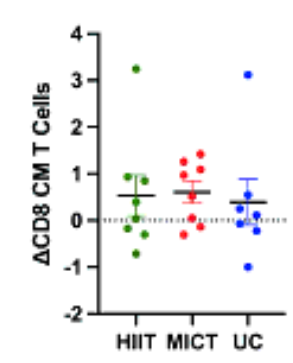

J

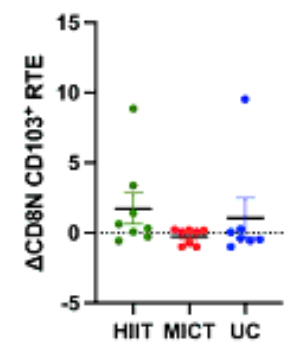

C

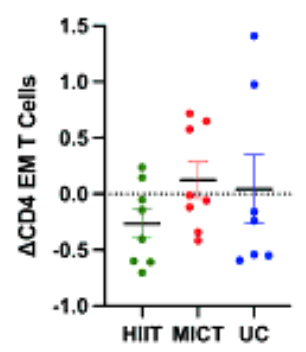

G

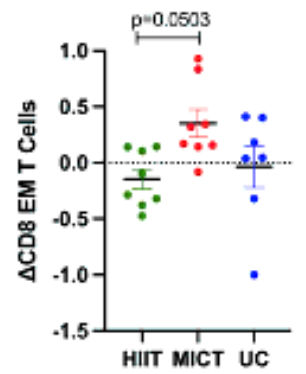

D

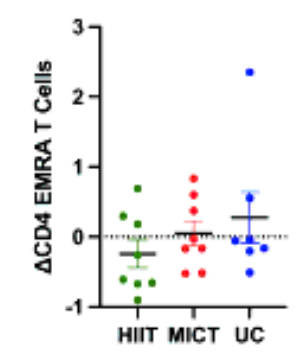

H

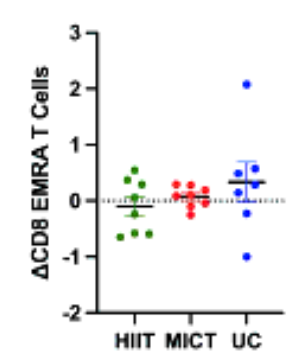

K

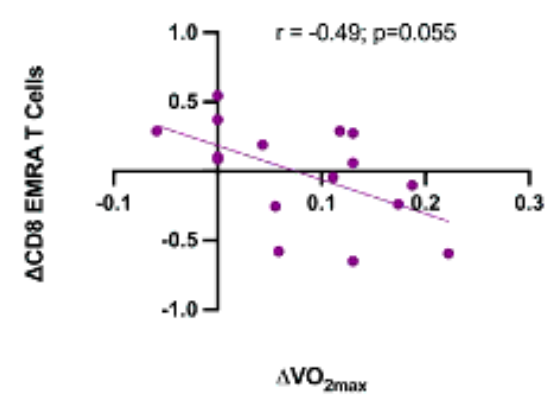

Figure 2

CD4 Naïve and Central Memory T cells are decreased with HIIT compared to MICT, and changes in fitness negatively correlate to changes in CD8 Effector Memory CD45RA+ T cells. Between group comparisons for differentiated $T$ cell subsets before and after exercise training in older women. (A-D) CD4 Subsets [ $N=$ naïve, $C M=$ central memory, $E M=$ effector memory, EMRA=Effector Memory CD45RA+], (E-H) CD8 Subsets [ $\mathrm{N}=$ naïve, $\mathrm{CM}=$ central memory, $\mathrm{EM}=$ effector memory, EMRA=Effector Memory CD45RA+], (I) CD4 Recent thymic emigrants (CD4N+CD31+), (J) CD8 Recent thymic emigrants (CD8N+CD103+). (K) Changes in fitness are negatively correlated to changes in CD8 EMRA T cells. Data are presented mean with * $\mathrm{p}<0.05$. 
A

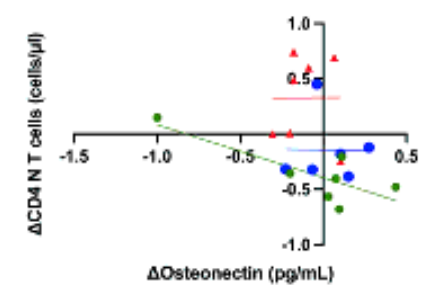

- HIIT $(r=-0.79, p=0.03)^{*}$

- MICT (r=0.004; $p=0.59)$

- UC $(r=0.17 ; p=0.97)$

C

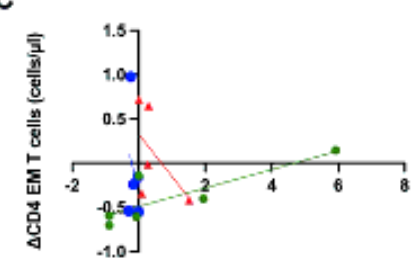

$\Delta \mathrm{IL}-15(\mathrm{pg} / \mathrm{mL})$

- $\operatorname{HITT}(r=0.84 ; p=0.0 .04)^{*}$

- MICT ( $r=0.55 ; p=0.34$

- UC ( $r=0.31 ; p=0.61)$

E

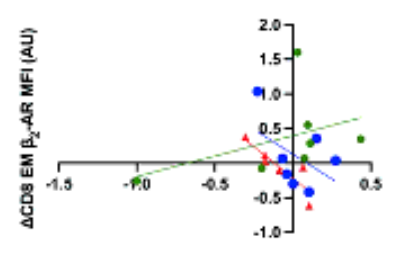

$\Delta$ Osteonectin [pg/mL)

- HIIT ira 0.44: $p^{=0.33)}$

* MICT $(r=0.87 ; p=0,03)^{\circ}$

- $U C(r=-0.48 ; p=0.28)$

G

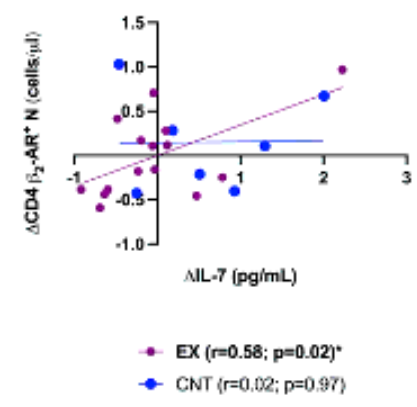

B

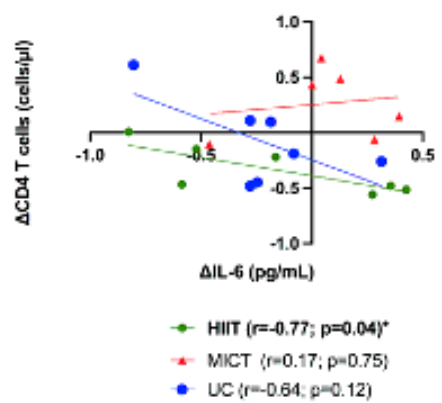

D

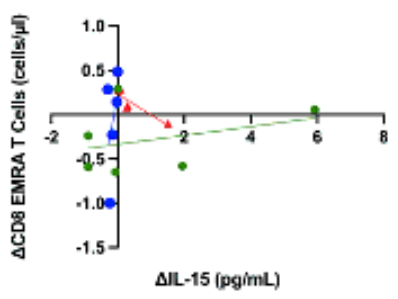

- HIIT (rm0.34; $p=0.51)$

* MICT $(r=-0.90 ; p=0.04)^{*}$

- UC $(r=0,46 ; p=01.44)$

$\mathbf{F}$

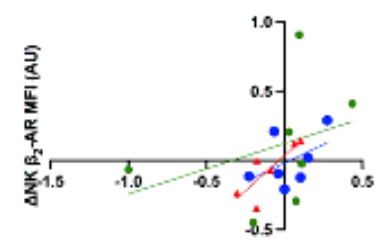

$\Delta$ Osteonectin [gg/mL]

- HIIT $(-\infty 6 ; p-0.43)$

* MICT (r=0.82; $p=0.046)^{*}$

- UC (m0.47; p-029)

H

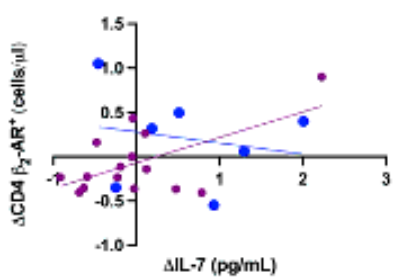

- $\operatorname{EX}(r=0.59 ; p=0.02)^{*}$

- CNT $(r=0.20 ; p=0.86)$

\section{Figure 3}

Changes in osteonectin, IL-6, IL-15 and IL-7, prominent myokines, are related to changes in immune cell subsets with exercise. (A, B) Changes in osteonectin and IL-6 were negatively related to changes in CD4 N T cells and CD4 T cells in the HIIT group only, respectively. $(C, D)$ Changes in IL-15 were negatively related to changes in CD4 EM T cells in the HIIT group only; and negatively related to changes in CD8 EMRA T cells in the MICT group only. (E, F) Changes in osteonectin were negatively related to changes in $\beta 2-A R$ 
expression CD8 EM T cells and positively related to changes in the $\beta 2$-AR expression on NK cells, respectively, in the MICT group only. (G, F) Changes in IL-7 were positively related to changes in $\beta 2-A R$ expression on CD4 N T cells and $32-A R$ expression on CD4 T cells in the exercise (HIIT+MICT; respectively) groups only. $\mathrm{N}=$ naïve, $\mathrm{CM}=$ central memory, $\mathrm{EM}=$ effector memory, $\mathrm{EMRA}=\mathrm{Effector}$ Memory CD45RA+. Lines represent line of best fit and were analyzed by Pearson's Correlation with $p<0.05$ considered statistically signification. ${ }^{\star} \mathrm{p}<0.05$.

A

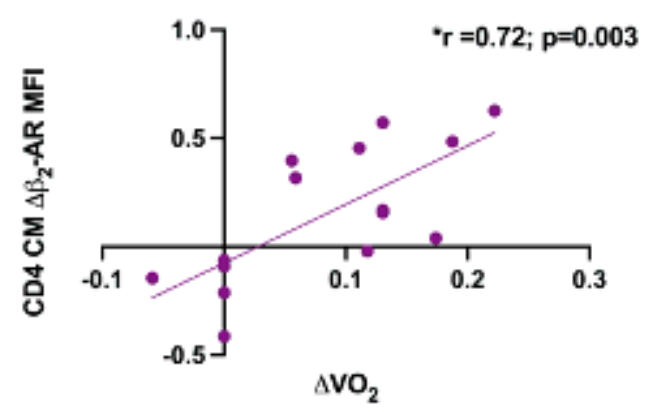

C

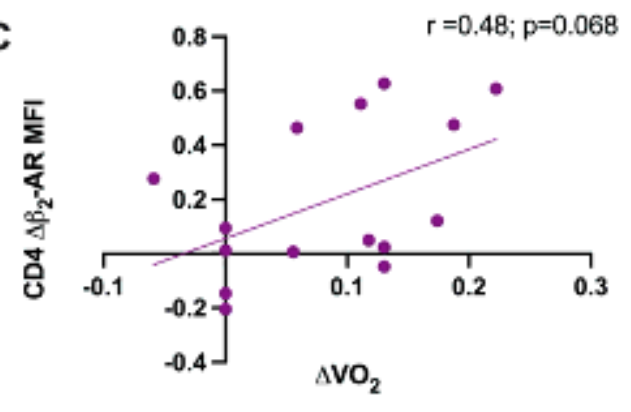

B

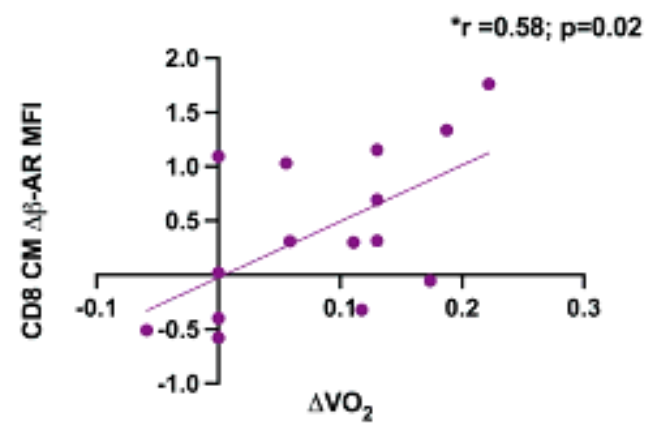

D

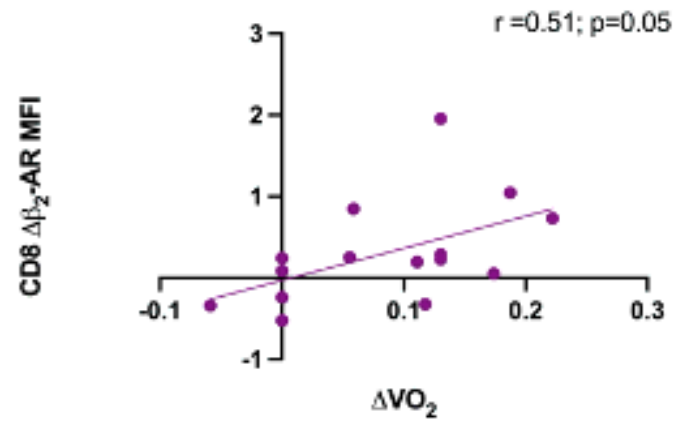

\section{Figure 4}

Changes in fitness are positively related to changes in 32 -AR expression on CD4 CM and CD8 CM Differentiated T cells in HIIT and MICT groups combined. Changes in fitness in the exercise groups were positively related to changes in (A) CD4 CM $\beta 2$-AR expression, (B) CD8 CM $\beta 2$-AR expression, (C) CD4 $\beta 2$ AR expression, and (D) CD8 $\beta 2-A R$ expression. [CM=central memory]. Lines represent line of best fit and were analyzed by Pearson's Correlation with $p<0.05$ considered statistically signification. ${ }^{*} p<0.05$. 